First publ. in: Cultural Transmission : Psychological,

Developmental, Social, and Methodological Aspects / Ute

Schönpflug (ed.). Cambridge, Mass.: Univ. Pr., 2009, pp. 126-160

\section{Intergenerational Relations and Cultural Transmission}

GISELA TROMMSDORFF

\section{INTRODUCTION}

Continuity and change of cultures over generations are affected by cultural transmission. The intergenerational transmission of culture refers to the way values, knowledge, and practices that are prevalent in one generation are transferred to the next generation. Cultural transmission, thus, is seen as a process by which the reproduction of culture occurs in each successive generation (Corsaro, 1997). However, the persistent reproduction of culture is only one aspect of (absolute) cultural transmission; another aspect is selective transmission. Transmission can be more or less intended and planned; it can also be a direct or indirect consequence of certain activities and events. Furthermore, the direction of transmission and its process can vary. Cavalli-Sforza and Feldman (1981) originally drew a distinction between horizontal (i.e., within one generation) and oblique (i.e., between generations) transmission; in other studies, horizontal transmission includes both (Hewlett \& Cavalli-Sforza, 1986). In line with research on socialization, more recent studies differentiate between three types of transmission: vertical transmission between parents and their offspring, oblique transmission functioning through socialization institutions and other agents (e.g., parents' peers), and horizontal transmission among peers (Berry, Poortinga, Segall, \& Dasen, 2002).

Intergenerational transmission has been seen as based on the relationship between different cohorts who share the same historical and socialization background but who are not biologically related (cf. Mannheim, 1929/1964).

The study on "Value of Children and Intergenerational Relations in Six Cultures" is supported by grants from the Deutsche Forschungsgemeinschaft (DFG) (Tr I69/4-I, 2, 3) (Principal investigators: Gisela Trommsdorff, University of Konstanz, and Bernhard Nauck, Technical University of Chemnitz). Beate Schwarz, Isabelle Albert, and Boris Mayer, University of Konstanz, are collaborating in this project. I am grateful to Holly Bunje who gave valuable suggestions to improve the English language.
The focus of psychologists is on individuals who belong to the same family interacting with each other in the process of intergenerational transmission. This perspective refers to the transfer of values and resources between different biologically related generations within a family (usually parents and their offspring but also grandparents and their grandchildren)

Although the direction of transmission is usually assumed to take place from the older to the younger generation, recent studies on parent-child relationships have identified bidirectional and indirect effects. This view gains special importance in the study of intergenerational cultural transmission and the respective intergenerational relations from a life-span perspective in the cultural context (Trommsdorff, 2006). Accordingly, intergenerational cultural transmission cannot be confined to unidirectional and static analyses. To predict the process, the direction, and the outcome of the cultural transmission for biologically related generations (i.e., belonging to the same family with partially shared genetic and environmental conditions), a comprehensive theoretical framework is needed.

Here, we start from an ecocultural model of intergenerational relations as the basis for cultural transmission. It is assumed that the process, direction, and outcomes of cultural transmission are affected by the persons (agents) who are involved in the transmission process, their respective relationships, the issues (contents) that are transmitted, and the cultural context in which transmission takes place. The effect of these variables on the cultural transmission may be direct or indirect. The outcomes of transmission can be described by continuity and selectivity in the transmission of culture.

The persons (i.e., parents and their children) involved in the transmission process influence the process and the outcome of the transmission on the basis of their preferences, beliefs, and competencies, including their cultural knowledge. Here, the socialization experience of these persons, their social status, and their developmental age are all relevant. The developmental status of the persons affects their intention and means of transmitting cultural values. Their acceptance of these values may change over time, such as when grown-up children become parents and thus influence the transmission of values.

The relationship of the persons involved in the transmission process influences its process and outcome, including continuity and selectivity. Therefore, the parent-child relationship is seen as the basic transmission belt (Schönpflug, 2007). This relationship can be based on emotional closeness or normative obligation, on harmony or conflict, on a hierarchical or vertical structure, on a long or short history of shared experiences, and on interdependence or independence (cf. Trommsdorff, 2006). A person-oriented approach is thus related to the relationship approach, taking into account the various qualities of relationships in the process of cultural transmission. 
Also, cultural transmission is assumed to depend on the contents of transmission and their respective importance for the individual person and for the culture, which can be related to more or less deep-rooted, important, widely shared, consistent, and well-integrated traditional values, cultural knowledge, and practices.

Furthermore, cultural transmission takes place in the wider context. The influence of these factors (i.e., persons, relationships, and contents) may differ depending on the conditions in the proximate or distant context. The contextual factors (e.g., heterogeneous or homogeneous, changing or stable societies) presumably affect the cultural beliefs and competence of the persons involved in the transmission process, their culture-specific relationship, and the cultural meaning of the topics to be transmitted. Multiple agents of transmission and their respective relationships can stabilize or undermine the vertical transmission of culture from one generation to the next, thus affecting cultural continuity. The oblique transmission may or may not coincide with the vertical transmission, and the horizontal transmission through peers may support or undermine the intergenerational transmission (Trommsdorff, 2006). Also, the wider socioeconomic and cultural context, including socioeconomic and cultural change (and crises) or continuity, may foster or constrain the intergenerational transmission and affect the impact of the previously mentioned moderating and mediating factors.

A theoretical framework of cultural transmission has to consider the relative and interactive effects of the persons involved in the transmission, their interpersonal relationships, the topics (i.e., contents) to be transmitted, and the contextual factors. For respective empirical studies, a complex design including at least three biologically related generations from different cultural contexts is necessary (Trommsdorff, 2001 a, 2001b, 2006; also see Section 4.0 in this chapter). To study the dynamic aspects of cultural transmission, taking into account individual development, changing relationships, and changing environments, a longitudinal study should complement this design. In this way, conditions and outcomes of cultural transmission, its selectivity, and its contribution to cultural continuity or change could be specified. The obviously related methodological difficulties may indicate why very few empirical data to test such a model are available at present. Accordingly, this chapter can deal with only selected aspects of the complex issue of cultural transmission, focusing on intergenerational relations in the life span in different cultural contexts.

The first part of this chapter discusses cultural transmission and socialization; the second part discusses intergenerational relations in the life span as a basis for the transmission of culture; the third part deals with transmission in cultural contexts; and the fourth part presents an empirical approach to the study of intergenerational relationships and cultural transmission in different cultures. Finally, these discussions are summarized with a focus on social change and cultural continuity.

\subsection{INTERGENERATIONAL CULTURAL TRANSMISSION AND SOCIALIZATION}

1.1. Intergenerational Transmission as a Socialization Process

Research on intergenerational transmission is often confined to dealing with processes and effects of socialization that do not go beyond traditional socialization theories. Sometimes intergenerational transmission and socialization are even used as interchangeable concepts. Our position is that socialization and transmission are not the same. Socialization is only a part of intergenerational cultural transmission insofar as it is part of the transmission belts and usually aims at ensuring a certain outcome.

Previous socialization research encountered several shortcomings that could be avoided by future research on intergenerational cultural transmission (for a summary, see Trommsdorff, 2006). One of the shortcomings was the one-sided approach to the nature-nurture controversy, ignoring the interactive effects of genetic dispositions and environmental factors (e.g., Plomin, 2000). In much socialization research, the biological basis of socialization, learning, and development has been ignored. At the same time, only very selective aspects of the environment have been considered - mainly, the proximate environment focusing on parents.

Another shortcoming of previous socialization research was the assumption of unidirectionality of parenting, emphasizing parental behavior (i.e., discipline) as influencing the development of the children. The traditional view of the child as a passive recipient of parental influences ignored interactions between parent and child in the process of development. Research has suggested a bidirectional approach to socialization and development (Kuczynski, 2003) and has also dealt with the intentional elements in socialization. The explanation of the effects of parenting (Baumrind, 1991) has made it necessary to also account for intentional processes focusing on parental goals and expectations as part of parental theories (Goodnow \& Collins, 1990). The perspective of the active role of the child (Bell, 1979; Maccoby \& Martin, 1983) assumes the child's intentional processes of learning and imitation (Bandura, 1977, 1986; Grusec \& Goodnow, 1994).

Another problem in traditional socialization research is the static view, focusing on the socialization of children and adolescents while ignoring further processes in adulthood from a life-span perspective.

A further shortcoming of socialization research was the neglect of the context in which development takes place. Only selected aspects of the proximate environment, usually the parents, were considered whereas the effects from the more distant environment were ignored. The neglect of contextual factors is a reason for another problem of previous socialization research: its ethnocentric bias. Most socialization theories have been empirically tested only in Western cultures, ignoring possible effects of the cultural context on socialization. This 
is surprising because early anthropological studies pointed out different socialization practices and processes in other cultures (Benedict, 1934; Mead, 1935). Also, Bronfenbrenner (1979) strongly suggested studying individual development from an ecotheoretical perspective, taking into account the interactive effects of the micro-, meso, macro-, and chrono-systems. However, only recently have interactive effects among the family and the other socializing agents (e.g., peers or school and other institutions) been studied as part of a complex system of socialization (cf. Bugental \& Goodnow, 2000; Collins, Maccoby, Steinberg, Hetherington, \& Bornstein, 2000; Maccoby, 2000).

Although socialization research cannot provide a sufficient basis for a theory on cultural and intergenerational transmission, research on intergenerational cultural transmission may profit from past shortcomings in socialization research.

\subsection{Intergenerational Transmission beyond Socialization Processes}

In this section, we suggest a theoretical framework for the intergenerational transmission of culture by studying processes and outcomes of transmission as based on intergenerational relations over the life span in cultural contexts. In this framework, the bidirectionality in the parent-child relationship is assumed to function as a transmission belt during the life span and within a wider cultural context.

1.2.1. Biological Basis of Intergenerational Transmission

The biological conditions of intergenerational transmission can be observed in early infant development. One biological basis of transmission was elaborated by attachment theorists (Ainsworth, Blehar, Waters, \& Wall, 1978; Bowlby, 1969), who asserted that a universal need for security and attachment in infants is related to the responsiveness of primary caretakers. When the caretakers provide the basis for secure attachment, the child can fulfill the need for curiosity and competence by exploration of the environment. This, in turn, fosters further social, emotional, and cognitive development over the life span (Thompson, 1999). Thus, attachment can be seen as a precondition for cultural learning and intergenerational cultural transmission including the partial transmission of attachment quality and possibly other aspects of intergenerational relations from one generation to the next (Trommsdorff, 2001a, 2002, 2006).

Social learning starts in early life through the biologically based ability for empathy (Gallese, 2003), shared attention, intentionality, understanding intentions of others (including theory of mind), and imitation (Meltzoff \& Moore, 1998). The biologically based precursors of cultural transmission can be observed in infants' ability to engage in and readiness for selective imitation. Tomasello, Kruger, and Ratner (1993) suggested three consecutive ontogenetic learning models for cultural learning: imitative learning (starting at 9 months), instructed learning (starting at about 4 years), and collaborative learning (starting at about 6 or 7 years). Keller (2002) adds another component, which is assumed to be prevalent during the first two and a half to three months of life: "structured learning," which is based on social interactions and directed by emotions. This results in approach or avoidance tendencies as a biological basis of cultural learning.

Furthermore, other studies have shown that the interplay between the endocrine architecture of one's life history and psychological outcomes during one's life course affect parental competence and child growth (Worthman, 1999).

\subsubsection{Interpersonal Basis of Cultural Transmission}

Transmission: Outcome or Process. One goal of research in cultural transmission has been to explain the continuity of cultural values transmitted from parents to their children. Intergenerational transmission, therefore, can be regarded as the children's acquisition and acceptance of values. Consequently, research on intergenerational transmission has usually focused on the "outcome" of transmission and the question as to whether the transmission was "successful." First, it is problematic to measure the outcome of transmission by simply focusing on similarities of single values between parents and their children without investigating whether transmitters are motivated to create similarity by their transmission efforts, as discussed in Sections 4.0 and 5.0. Second, the focus on outcomes only catches one aspect of transmission and ignores the processes and direction of transmission, which may provide a more interesting approach in understanding the functionality and meaning of the "outcomes."

Transmission Processes: Unidirectionality in Intergenerational Transmission. The process of transmission has been explained in two ways: by assuming a unidirectional process of parents influencing their children and by assuming bidirectional processes including interactions between children and parents.

The first approach usually assumes that the outcome is intended by the parents while ignoring the children's intentions. This approach regards parenting as the main transmission belt. The focus of these studies is on the parents' behavior and their (direct) effects on the child's "internalization" of parental values.

Beyond Unidirectionality in Intergenerational Transmission. The second approach regards both parents and children as the transmission belt, assuming that transmission takes place on the basis of the activity of both the parents and the child. The model of internalization by Grusec and Goodnow (1994) is very fruitful for a theory on transmission belts; they assert that the child actively participates in the socialization process by interpreting, evaluating, either accepting or rejecting the parents' message, and, finally, possibly conforming and internalizing the message, thus matching their own intentions with those of their parents. 
Furthermore, the child's behavior influences the way the parents interact with the child. This assumption of bidirectionality became the focus of socialization and internalization theories (Grusec \& Kuczynski, 1997; Kuczynski, 2003). It allows for more refined predictions of transmission processes and can be seen as part of the model of internalization. It offers a fruitful approach to the explanation of intergenerational transmission as based on bidirectional intentionality.

Beyond Bidirectionality and Interactions in Intergenerational Transmission The acknowledgment of the child's intentionality and activity in the process of development is seen here as a promising but not sufficient component for a theory on cultural transmission. A further precondition for successful transmission beyond the bidirectionality between child and parent is the quality of the parent-child relationship.

Successful internalization is predicted when the child feels accepted, when he or she regards the parents as adequate models, and when the parents communicate the message clearly. These are relevant aspects of the parent-child relationship that traditional socialization research has ignored. Thus, the study of intergenerational and cultural transmission has to go beyond the bidirectional perspective and consider intergenerational relations over the life span and in the cultural context. These are the topics of the next section.

\subsection{INTERGENERATIONAL RELATIONS OVER THE LIFE SPAN}

\subsection{Theoretical Approach to Intergenerational Relationships}

Why are intergenerational relations considered important for cultural transmission? It is assumed here that relationships between parents and their children can explain the direction, the process, and the outcome of intergenerational cultura transmission. Here, we conceptualize parent-child relationships as lifelong, biologically constituted personal relationships; they are based on interconnected experiences in the past and the expectation of interconnected experiences in the future. Parent-child relationships constitute the most extended relationships on the dimension of time, and their quality may change over the life course. They are only partially voluntary and start from an asymmetric distribution of This view on parent-child relationships as a transmission belt implies that cultural transmission can affect both parents and their children.

Parent-child relationships differ from other relationships. They are not the ame as intimate and close voluntary personal relationships. For decades, explain close relationships (Homans, 1961; Kelley, 1983; Kelley \& Thibaut, 1978; Thibaut \& Kelley, 1959). Biological and evolutionary approaches (e.g., attachment theory; see Ainsworth et al., 1978; Bowlby, 1969) stimulated criticism to the traditional exchange theoretical approach; for example, the interdependence theory on close relationships (Rusbult \& Van and commitment as influencing prosocial orientations and the persistence of the relationship. Beyond this approach, the importance of culture for the explanation of close relationships was suggested by Rothbaum, Pott, Azuma, Miyake, and Weisz (2000) and Trommsdorff (1995b, 2001a). We assume here that shared beliefs and goals related to the cultural context are a basic component of close relationships (Trommsdorff, 1991, 2001a). Those cultural beliefs, in turn, affect the process and the outcome of transmission.

\subsection{Life-Span Approach to Parent-Child Relationships}

From a life-span perspective, the question of how changes in intergenerational relations influence cultural transmission gains new meaning. Life-span approaches deal with changing developmental tasks and normative life events (Havighurst, 1972); life stages, transitions, and crises (Erikson, 1959); continuity and change of biological, cognitive, emotional, motivational, and social domains of the person; and selective optimization in multidimensional development (Baltes \& Baltes, 1990). These approaches are usually applied to individual development but can also be related to changes and stability of parent-child relations during the life span and effects on cultural transmission.

First, we discuss this topic from the point of view of Western developmental theories. In Section 3.0, we focus on the limitations of this approach by considering the cultural context.

From early childhood to adolescence, asymmetry in parent-child relationships is assumed to become increasingly transformed into symmetric partnerships. This implies conflicting interests and negotiations between parents and children in the pursuit of individuality and individual needs fulfillment. From the Western perspective, parents are viewed as pursuing the goal of establishing their children's independence while simultaneously striving for continuity of values by having their children adopt their values. These seem to be inherently contradictory goals. The transmission of values in a context in which independence is highly valued does not necessarily imply conformity to parental values. Accordingly, the developmental task of adolescents has often been seen as establishing a unique identity distinct from that of their parents and of achieving autonomy. Emotional, attitudinal, conflictual, and functional independence are seen as the core elements in the process of separation-individuation (Hoffman, 1984).

How can these processes foster cultural transmission from parents to children? It seems quite plausible that cultural transmission only occurs selectively under this condition. Recent studies that have criticized the separationindividuation assumption and its individualistic bias argue that both autonomy from and relatedness to the parents is a more appropriate description for parentchild relationships in this developmental period. Because the connection to the parents is seen as a relevant precondition for the individuation process (Cooper, Grotevant, \& Condon, 1983), the rebalancing of individuality and 
connectedness permits the achievement of individuated relationships. At the same time, the parents themselves undergo certain developmental changes from their role as caretakers to the role as facilitators of their child's development (Cooney, 1997).

During further development, oblique and horizontal cultural transmission occurs and may moderate the vertical transmission process, which is increasingly characterized by bidirectional intentional influences and negotiation. Young adulthood has often been described by processes of negotiation between parents and offspring in order to ensure the independence of the children and reduce conflicts in parent-child relationships.

Parent-child relationships in middle adulthood are usually characterized by the adult offspring having their own children (i.e., the "sandwich generation"). Neugarten (1968) conceived of mid-life development as growing responsibility in the now more extended family. Related changes in the quality of the parentchild relationship gain importance as a result of a third separation-individuation process, when the adult parents grow older, retire from work, take on the role of grandparents, or experience psychological and cognitive dependency. These changes in later adulthood and old age again affect the relationships among the aging parents, their adult children, and their grandchildren.

The changing quality of the parent-child relationship in mid-life was conceptualized by Blenkner (1965) as the development of "filial maturity." In this period, the relationship between adult children and their parents is less influenced by the social norm of parental roles and more by the perceived personal needs of the aging parents.

Filial autonomy, the degree of reciprocity between the parent and the adult child, and the overall interdependence of the family members can be assumed to affect processes of cultural transmission over the life course.

\subsection{Parent-Child Relationships over the Life Span and Cultural Transmission in a Changing Context}

A serious shortcoming of research on parent-child relationships is the neglect of contextual factors. Parent-child relationships develop within a wider family system and are affected by the wider socioeconomic and cultural context. They take place in changing contexts, which imply changing developmental tasks over the life course (e.g., Crocket \& Silbereisen, 2000; Elder, 1974, 1998; Trommsdorff, $2000,2001 \mathrm{a}, 2001 \mathrm{~b}, 2003$ ). These studies provide insight about risk and buffering factors for development of family members interacting in a context of linked lives, which again are affected by the wider socioeconomic and cultural contexts. The changing structure of intergenerational relationships (e.g., parent-child grandparent-grandchild) can still be seen as a transmission belt allowing for the continuation of family members' interconnected "linked lives" over the life course (e.g., Elder, 1998).
The question now arises about the effects of the changing environment on intergenerational cultural transmission. This question is especially relevant in times of dramatic socioeconomic and demographic changes such as increasing longevity and a related gender gap in life expectancy, decreasing fertility and increasing postponement of first-child birth, decreasing family stability, and increasing diversity of family structure (e.g., due to divorce, single-parent families, second or third marriage, changing gender roles) (cf. Bengtson, 2001; Trommsdorff \& Nauck, 2005; Zarit \& Eggebeen, 2002). Due to the worldwide increase in longevity, parents and children will share on average almost five decades as adults.

The impact of social and economic changes on intergenerational relations, including those between grandparents and grandchildren, can include changes in vertical or horizontal economic transfers and investments (Kohli \& Szydlik, 2000), changes in the relationship quality (including emotional closeness, solidarity between the generations, patterns of intergenerational exchanges and support, family eldercare), and changes in the continuity or discontinuity of intergenerational relations over time, as well as similarities and differences between the generations with respect to values (e.g., Bengtson \& Robertson, 1985; Cooney, 1997; King \& Elder, 1997; Trommsdorff, 2006; Zarit \& Eggebeen, 2002).

Rapidly changing cultural contexts can even induce a reversal in the direction of cultural transmission. Adolescents' adoption of changing cultural values can initiate a change in the direction of transmission, thereby effecting changes in the values, beliefs, and behavior of their parents. These value changes may enter into the intergenerational transmission of values to the youngest generation the grandchildren. Results from our studies actually point to more similarities among grandparents and adolescent grandchildren than among grandparents and their adult children (Trommsdorff, Mayer, \& Albert, 2004). Thus, intergenerational relationships can be seen as a source of change in the process of cultural transmission (Kuczynski \& Navara, 2006; Valsiner, 1988). This view again takes seriously the active role of the child in the process of transmission and internalization (on the basis of bidirectionality), the function of intergenerational relationships in the life span and in the process of changing contexts, and the heterogeneity and dynamic nature of cultures and societies.

\subsection{CULTURAL CONTEXT AND THE INTERGENERATIONAI} TRANSMISSION OF CULTURE

The transmission of values (via socialization, internalization, or the like) and intergenerational relationships are embedded in a wider socioeconomic and cultural context. The transmission belts are affected by cultural values while also affecting the transmission of such values. A deficit in previous research on transmission has been the neglect of the wider social and cultural context in 
which it takes place. This is surprising because more than 80 years ago, early anthropological studies (e.g., by Ruth Benedict, Margaret Mead, Beatrice B. Whiting, and John W. M. Whiting) noted that different socialization practices and parent-child relationships, which are related to different child outcomes, can be observed in non-Western cultures. Only more recently has the question been posed whether transmission theories empirically tested in the Western world can be generalized to other cultural contexts (Bugental \& Goodnow, 2000; Rothbaum \& Trommsdorff, 2007; Rothbaum, Weisz, Pott, Miyake, \& Morelli, 2000; Trommsdorff \& Kornadt, 2003). Studies on acculturation also provide insight about the impact of contextual factors in the process of cultural transmission (see Knafo \& Schwartz, chapter 11, and Schönpflug, chapter 2, this volume). A culture-informed approach to intergenerational transmission considers the culture-specific aspects of socialization, internalization, and intergenerational relationships. First, a general theoretical approach to culture and development is suggested. Second, culture-informed studies on parenting and parent-child relationships as a part of cultural transmission are discussed.

\subsection{Culture and Individual Development}

The transmission of culture is a traditional topic in cultural anthropology. For example, LeVine (1973) states:

The transmission of culture from generation to generation is, in Mead's (1935) view, a process of communication in which many aspects of the growing individual's cultural environment relay ... messages reflecting the dominant configurations of his culture... They enter into communication with him by making certain (culturally approved) reactions to his cries, his performance of bodily functions, his attempts to move and grasp; much of this communication is nonverbal and implicit. It lays a basis for the later transmission of the same underlying messages in a thousand other ways, some of them explicit, as the child increasingly participates in the various aspects of adult culture. Child rearing is fundamental in the acquisition of cultural character, but it is only the first of many formative experiences, each reinforcing the other in communicating cultural configurations to the individual (p. 54).

In contrast to most theories of socialization that are confined to Western cultures, the question of the transmission of culture is related to the general question of how individual psychological processes are related to culture (Bruner, 1996). Some authors assume a unidirectional influence of culture on the mind. The traditional model of the tabula rasa fits with this notion. At the other extreme, culture and mind are seen as being interdependent and interconnected (Cole, 1996).

From the first perspective, the person is more or less the recipient of cultural influences. Empirical research on transmission of culture follows this approach and starts from a quasi-experimental design, comparing different cultures and related forms of transmission with respect to their effects on the person. This approach attempts to generalize empirical findings on causal relations across cultures and is typical of cross-cultural research and its nomothetical methodological basis. From the second perspective, the person actively constructs culture while also being affected by culture.

These perspectives have long been viewed as mutually contradictory. In the same line of reasoning, the assumptions of a "psychic unity of mankind" and "cultural relativism" contradict each other. However, for a culture-informed study of cultural differences and similarities, it is essential to consider culturespecificities in methods, data analyses, and interpretation of the data, thus combining an "etic" and an "emic" perspective (for an overview, see Trommsdorff \& Friedlmeier, 2004; Trommsdorff \& Mayer, 2005). The study of the transmission of culture could be seen as constructively connecting the "emic" and "etic" approaches, focusing on the individual person and intergenerational relations in cultural transmission. Accordingly, questions on the universality of (selective) cultural transmission can only be answered when taking into account the cultural context.

How to describe cultures? The study of the transmission of culture must deal with the difficult concept of culture. In anthropological research, more than 100 definitions of culture have been suggested (Kroeber \& Kluckhohn, 1952). Benedict (1934) introduced the notion of "cultural pattern," whereas others preferred the notion of cultural models (D'Andrade \& Strauss, 1992; Holland \& Quinn, 1987; Shore, 1996), cultural templates (or schemata) (Geertz, 1973), or cultural practices (Shore, 1996). Cultural transmission thus includes the transmission of such cultural practices and knowledge. This process may follow more or less strict rules and thus preserve continuity or induce change.

From a psychological point of view, a definition of culture seems futile unless the psychological aspects of culture relative to the individual person are specified in terms of functional relationships (Trommsdorff \& Friedlmeier, 2004). According to Geertz (1973), culture is a semiotic system (of meanings) and functions as an external control system for human behavior; it is seen as a selective factor in the evolutionary process and not as the final product. A psychological approach conceives of the function of culture as a factor in the process of sociocultural change and individual development. Depending on the cultural context, the transmission of culture can be more or less constrained and thus ensure, respectively, continuity or change. Accordingly, cultural transmission is studied herein with respect to the transmission of cultural models and knowledge in the process of individual development and intergenerational relationships in context.

What are the contents of cultural transmission? A psychologically relevant definition of culture cannot avoid the question of the relationship between culture and mind (Bruner, 1996). Shore (1996) attempted to study culture and mind 
Also, cultural transmission is assumed to depend on the contents of transmission and their respective importance for the individual person and for the culture, which can be related to more or less deep-rooted, important, widely shared, consistent, and well-integrated traditional values, cultural knowledge, and practices.

Furthermore, cultural transmission takes place in the wider context. The influence of these factors (i.e., persons, relationships, and contents) may differ depending on the conditions in the proximate or distant context. The contextual factors (e.g., heterogeneous or homogeneous, changing or stable societies) presumably affect the cultural beliefs and competence of the persons involved in the transmission process, their culture-specific relationship, and the cultural meaning of the topics to be transmitted. Multiple agents of transmission and their respective relationships can stabilize or undermine the vertical transmission of culture from one generation to the next, thus affecting cultural continuity. The oblique transmission may or may not coincide with the vertical transmission, and the horizontal transmission through peers may support or undermine the intergenerational transmission (Trommsdorff, 2006). Also, the wider socioeconomic and cultural context, including socioeconomic and cultural change (and crises) or continuity, may foster or constrain the intergenerational transmission and affect the impact of the previously mentioned moderating and mediating factors.

A theoretical framework of cultural transmission has to consider the relative and interactive effects of the persons involved in the transmission, their interpersonal relationships, the topics (i.e., contents) to be transmitted, and the contextual factors. For respective empirical studies, a complex design including at least three biologically related generations from different cultural contexts is necessary (Trommsdorff, 2001 a, 2001b, 2006; also see Section 4.0 in this chapter). To study the dynamic aspects of cultural transmission, taking into account individual development, changing relationships, and changing environments, a longitudinal study should complement this design. In this way, conditions and outcomes of cultural transmission, its selectivity, and its contribution to cultural continuity or change could be specified. The obviously related methodological difficulties may indicate why very few empirical data to test such a model are available at present. Accordingly, this chapter can deal with only selected aspects of the complex issue of cultural transmission, focusing on intergenerational relations in the life span in different cultural contexts.

The first part of this chapter discusses cultural transmission and socialization; the second part discusses intergenerational relations in the life span as a basis for the transmission of culture; the third part deals with transmission in cultural contexts; and the fourth part presents an empirical approach to the study of intergenerational relationships and cultural transmission in different cultures. Finally, these discussions are summarized with a focus on social change and cultural continuity.

\subsection{INTERGENERATIONAL CULTURAL TRANSMISSION AND SOCIALIZATION}

1.1. Intergenerational Transmission as a Socialization Process

Research on intergenerational transmission is often confined to dealing with processes and effects of socialization that do not go beyond traditional socialization theories. Sometimes intergenerational transmission and socialization are even used as interchangeable concepts. Our position is that socialization and transmission are not the same. Socialization is only a part of intergenerational cultural transmission insofar as it is part of the transmission belts and usually aims at ensuring a certain outcome.

Previous socialization research encountered several shortcomings that could be avoided by future research on intergenerational cultural transmission (for a summary, see Trommsdorff, 2006). One of the shortcomings was the one-sided approach to the nature-nurture controversy, ignoring the interactive effects of genetic dispositions and environmental factors (e.g., Plomin, 2000). In much socialization research, the biological basis of socialization, learning, and development has been ignored. At the same time, only very selective aspects of the environment have been considered - mainly, the proximate environment focusing on parents.

Another shortcoming of previous socialization research was the assumption of unidirectionality of parenting, emphasizing parental behavior (i.e., discipline) as influencing the development of the children. The traditional view of the child as a passive recipient of parental influences ignored interactions between parent and child in the process of development. Research has suggested a bidirectional approach to socialization and development (Kuczynski, 2003) and has also dealt with the intentional elements in socialization. The explanation of the effects of parenting (Baumrind, 1991) has made it necessary to also account for intentional processes focusing on parental goals and expectations as part of parental theories (Goodnow \& Collins, 1990). The perspective of the active role of the child (Bell, 1979; Maccoby \& Martin, 1983) assumes the child's intentional processes of learning and imitation (Bandura, 1977, 1986; Grusec \& Goodnow, 1994).

Another problem in traditional socialization research is the static view, focusing on the socialization of children and adolescents while ignoring further processes in adulthood from a life-span perspective.

A further shortcoming of socialization research was the neglect of the context in which development takes place. Only selected aspects of the proximate environment, usually the parents, were considered whereas the effects from the more distant environment were ignored. The neglect of contextual factors is a reason for another problem of previous socialization research: its ethnocentric bias. Most socialization theories have been empirically tested only in Western cultures, ignoring possible effects of the cultural context on socialization. This 
by relating “ . . b both 'external' institutions (culture-in-the world) and 'internal' mental representations (culture-in-the-mind)" (p. 5), conceptualizing culture in mind. According to Shore (1996), instituted models (i.e., institutionalized, objectified, and publicly available shared arrangements or empirically observable social institutions) are part of the external social world. They can organize the development of mental models in the newly socialized persons and can become (more or less) conventional mental models. However, these mental representations are not simply a copy of the cultural model, they are rather underlying complex processes of "meaning construction"; they are products of intentional behavior (p. 51).

The relationship between both the institutionalized and the mental models is complex. When cultural models are transformed into individual mental models, they undergo significant transformations. Accordingly, Shore (1996) poses three questions: (1) How are public forms of knowledge or culturally mediated mental models transformed into personal mental models?; (2) How do cultural practices connect models in the world to those in the mind?; and (3) What happens to those mental models during the transformation process? Because dominant cultural models can be challenged by alternative (counter) models, a further question concerning the selective transmission comes up: Why and how is which cultural model transformed into a personal model?

\subsection{Cultural Transmission Belts}

The underlying psychological question relevant to this chapter is how the transmission of culture functions. Culture provides various transmission belts (Schönpflug, 2001) or modes of acquiring the cultural "model" or scripts. In a more general sense, transmission takes place on the basis of shared cultural beliefs. In his famous Völkerpsychologie, Wundt (1900-1920) described how cultural beliefs are connected to certain symbols and rituals. For example, people who have the same totem belong to one family or to one tribe; they share the same cultural beliefs and practices and are involved in the transmission of those beliefs to the next generation.

Transmission of culture has been conceptualized as the repetition of the same idea in various contexts (i.e., "thematicity") (Quinn \& Holland, 1987). This repetition may consist of practicing a certain behavior that is part of the family tradition, such as the lifelong practice of an art or artist production (e.g., Noh play in Japanese families). Repetition of cultural practices is part of the apprenticeship model (Rogoff, 2003). Another approach to explaining transmission of culture in other contexts was described by Vygotsky (1962) and Greenfield (2000) as "guided participation" of children in the world of adults. This is mostly the case in traditional cultures in which transmission belts are based on model learning and imitation of behavior rather than following abstract principles.
In this chapter, the focus is on cultural transmission based on biological intergenerational relationships. Traditionally, transmission of heritage, material, and cultural knowledge takes place in the family. Cultural transmission through biological and family relationships can be explained through the cultural and, hence, psychological meaning (e.g., the value of the family, children, and parentchild relationships). For example, in some cultures, biological relationships are less important for the transmission of cultural practices in cases where no male child is born. The adoption of a child (usually male) can become the basis for establishing an in-group family-like relationship; this compensates for the lack of biological continuation of the family, ascribing the role of a successor to the adopted child. Thus, the active construction of transmission (beyond the biologically based parent-child relationship) is part of the respective cultural belief system.

Accordingly, transmission has been viewed as being affected through "ethnopsychology" (Shore, 1996). This is in line with Bruner's (1996) view on the interrelation between culture and mind: "... How a people believe the mind works will... have a profound effect on how in fact it is compelled to work if anybody is to get on in a culture" (p. xvii). Here, it is assumed that the subjective beliefs of socialization agents (e.g., parents and teachers) as part of the cultural meaning system will affect the next generation's beliefs, "meaning making," and behavior, thus constituting "reality" (Bruner, 1996).

Universally, people develop theories to help them understand and respond to the world around them. These naive theories usually reflect the shared beliefs of people who live in a given culture or environment. Such naive ethnotheories are central to thinking and behavior and include cultural contents transmitted from one generation to the next. This assumption underlies the theoretical approach of Super and Harkness (1999; Harkness \& Super, 2002), who describe the function of the developmental niche as a part of culturally based transmission. This assumption also underlies our own research on subjective theories and parental beliefs in the cultural context (Trommsdorff \& Friedlmeier, 2004) and further cross-cultural studies on the intergenerational transmission of values (Albert, 2007; Trommsdorff, 2001a, 2002, 2007; Trommsdorff, Mayer, \& Albert, 2004) (see Section 4.0).

Considering the culture-specific meaning system, the problem of universality or culture-specificity in transmission must be addressed. According to Berry (1967) and Cole and Scribner (1974), even basic processes of perception are "modeled" by a specific cultural context (e.g., different optical illusions of people raised in carpentered environments - straight lines, regular angles - versus "natural environments" - without artificial lines and no experience of twodimensional perception). Shore (1996) suggested that these "cultural models" (D'Andrade \& Strauss, 1992; Holland \& Quinn, 1987) can be thought of as "cultural affordances" (p. 6) equivalent to physical affordances in the natural environment. 
The debate about the universality or relativity of psychological processes is shortsighted when it focuses only on fully determined, universally shared processes or only on the variability and the seemingly arbitrary nature of cultural practices (Shweder, 1991). Shore (1996) suggested a third alternative, namely that "cultural phenomena are better characterized as conventional arrangements that may or may not be arbitrary" (p. 37). Accordingly, cultural practices are conceived of herein as human creations that are constrained and that vary within these constraints.

\subsection{Cultural Pathways for Intergenerational Relationships} and Cultural Transmission

Therefore, we suggest an integrated ecocultural and developmental approach to study parent-child relationships as part of cultural pathways (Trommsdorff, 2006, 2007). The respective cultural contexts are regarded as providing both certain constraints and opportunities for the development of parent-child relationships: (1) the ecocultural approach differentiates among several levels of the macro-, meso-, and micro-system (Bronfenbrenner, 1979); (2) the value approach differentiates between cultural values (e.g., independence and interdependence) (Kagitcibasi, 1996; Triandis, 1995); and (3) the model of the developmental niche describes proximate developmental factors such as parental ethnotheories and practices (Harkness \& Super, 2002; Super \& Harkness, 1999). These approaches can be integrated in a cultural model on developmental paths focusing on autonomy and relatedness in close parent-child relationships (Rothbaum, Pott et al., 2000; Rothbaum \& Trommsdorff, 2007; Trommsdorff, 2006, 2007).

Independence and Interdependence as Basic Values. The relationship between culture and parent-child in the process of cultural transmission can be seen on various levels: Cultural values can influence and regulate parent-child relationships over the life span, and parent-child relationships can influence the development and change of value orientation in the child and in the parents. They can thereby affect the transmission of values to the next generation, which in turn affects the cultural value system. Thus, cultural values can be seen not only as input and output variables but also as a moderator affecting the quality of the parent-child relationship and the transmission. Accordingly, cultural values can be studied on various levels: At one level, the cultural values are represented in cultural meaning systems, rituals, and artifacts; at another level, the individual value orientations are represented by individual belief systems, goals, intentions, and individual behavior. Thus, the focus of research can be either on the macro-, micro-, or group level or on the level of the individual person (Bronfenbrenner, 1979; Matsumoto, 1999; Triandis, 1995).

Cultures and individual members of a culture can differ with respect to their values in regard to the self and the role of the person relative to the family and society. In certain cultures, the person tends to experience himself or herself as rather separate from others; in other cultures, the person experiences himself or herself as interconnected, especially with members of the family and the in-group. These different qualities were conceptualized as independence and interdependence (Markus \& Kitayama, 1991, 1994). In some cultures, a clear preference for independence and autonomy is highly valued, whereas in other cultures, interdependence and relatedness are preferred. This distinction of culture-specific value orientations has proven useful for the explanation of cultural differences in self-development, in the development of emotions and cognitions, in the development of interpersonal interactions and relations (Fiske, Kitayama, Markus, \& Nisbett, 1998; Greenfield, Keller, Fuligni, \& Maynard, 2003; Rothbaum, Pott, et al., 2000; Rothbaum, Weisz, et al., 2000; Trommsdorff \& Dasen, 2001; Trommsdorff \& Rothbaum, 2008), and in family systems (Kagitcibasi, 1996). The culture-specific values of independence and interdependence affect the meaning of aspects of parent-child relationships such as relatedness, control, and autonomy.

Parent-child relationships can vary along assurance versus trust (Rothbaum, Pott, et al., 2000; Yamagishi, Cook, \& Watabe, 1998). Some cultures are based on the need for assurance, which is related to close kin networks and an incentive structure for members of the in-group; this builds a sense of obligation, unconditional loyalty, and filial piety. In contrast, other cultures are based on the need for security, which is related to changing in-groups and weak group ties, while there is hope for commitment (in the absence of assurance). Here, contracts or intimacy serve as the basis for close relationships. These very different qualities underlie the two types of relationships, characterized by different meanings and dynamics of relatedness (Rothbaum \& Trommsdorff, 2007).

\subsection{Cultural and Developmental Paths of Intergenerational Relationships over the Life Span}

3.4.1. The Cultural Meaning of Parent-Child Relationships and Parenting A culture-informed theory on parent-child relationships and cultural transmission has to consider the culture-specific meanings of the respective behavioral indicators. This was the starting point for the culture-informed theoretical modification of attachment theory by Rothbaum, Weisz, et al. (2000). The authors question the universality of the assumed concepts that underlie attachment theory and their culture-insensitive operationalization (e.g., caretakers' sensitivity) but do not question the universality of attachment theory.

Cross-cultural studies show that bidirectionality in parent-child relationships can have different meanings in different cultures (Trommsdorff \& Kornadt, 2003). The Western view is usually confined to interpersonal negotiations between parents and children on the basis of relatively independent positions. However, in many East Asian cultures, parents' and children's roles are 
embedded in a hierarchical structure; the level and function of these roles prescribe certain behavior (Chao \& Tseng, 2002; Trommsdorff \& Kornadt, 2003). This behavior is embedded in a stable relationship of mutual obligation and based on emotional interdependence, as indicated by the concepts of filial piety and reciprocity (e.g., Kim, Kim, \& Hurh, 1991; Schwarz, Trommsdorff, Kim, \& Park, 2006; Wang \& Hsueh, 2000).

Also, cross-cultural studies show that the "same" parenting may have different meanings in different cultures, and different parenting may have the same meaning in different cultures (Kornadt \& Trommsdorff, 1984; Trommsdorff \& Kornadt, 2003). For example, harsh punishment of children is seen as harmful for child development in Western cultures whereas it is positively valued in traditional Chinese families (Stevenson, Chen, \& Lee, 1992; Stevenson \& Zusho, 2002). In several East Asian (Japan) and Southeast Asian (Indonesian) cultures, as compared to Western (German) cultures, adolescents report more parental control and, at the same time, less conflict and more harmony in the parent-child relationship (Trommsdorff, 1995a).

These differences do not speak to cultural meaning unless the function of this parental behavior is studied. Cross-cultural studies show that the same parental behavior and goals may have different functions in different cultural contexts, thus underlining the culture-specificities of parent-child relationships (for Asians, see the overview by Chao \& Tseng, 2002). Our own studies on adolescents from different cultures showed that Japanese as compared to German youths felt rejected by their parents when experiencing low parental control (Trommsdorff, 1985). Similar results of Koreans living in North America compared to Koreans living in the Republic of Korea were reported by Rohner and Pettengill (1985). Results on negative effects of parental control on children and adolescents cannot be generalized across cultures but rather must be interpreted in an integrative, culture-informed theoretical framework on parent-child relationships.

From a culture-informed point of view, the basic cultural difference in parentchild relationships depends on whether observed behavior patterns are intended to establish and stabilize interdependent relationships based on cooperation and harmony or whether they are intended to develop independent relationships including conflicts and negotiations of power (Rothbaum, Pott, et al., 2000). These intentions are based on relevant experience in the past and they shape expectations for the future. A typical example would be an interaction sequence between a mother and a child in the case of conflicting goals (resulting in "misconduct" of the child) in a Japanese and a German dyad. This interaction sequence usually ends with the Japanese mother giving in whereas a conflict prevails in the German dyad (Trommsdorff \& Kornadt, 2003). In Japan, the value of interdependence and maintaining harmonious relationships prevails, whereas in Germany, the value of independence dominates. The culture-specific parental intentions are part of the individual value system, constituting both the transmission belt and the (intended) outcome of the transmission process.
3.4.2. Culture-Specific Developmental Paths in Parent-Child Relationships Starting from cultural differences in parent-child relationships, Rothbaum, Pott, et al. (2000) suggested a culture-specific model of development in Japan and in the United States representing a social-oriented and an individualist culture. The authors describe very different patterns of parent-child relationships based on needs for separation or closeness, for independence or interdependence, and for autonomy or relatedness. Consequently, either self-oriented or other-oriented goals characterize the cultural differences in those relationships. The authors are less interested in describing differences in the importance and strength than in differences in the meaning and dynamics of close relationships. The authors view the biological predispositions for relatedness as "passing through cultural lenses" during development (p. 1123). These cultural lenses are based on cultural values that emphasize interdependence and accommodation or independence and individuation. They affect the development of close relationships. Accordingly, the authors identify two prototypes: the symbiotic harmony and the generative tension (p. 1123). The cultural value of symbiotic harmony is based on the desire to maintain interdependence by fulfilling one's duties, by compliance with parents' wishes, and by meeting social expectations. For example, parent-child relationships in Japan are based on interdependence and characterized by harmony, cooperation, mutual obligations, and the need to reciprocate (Trommsdorff, 2006; Trommsdorff \& Kornadt, 2003).

In contrast, the prototype of generative tension (which can be observed in the mother-child relationship in the United States) is based on the desire to establish and maintain independence and fulfillment of individual goals. Here, parent-child relationships are based on partnership, acceptance of conflicts, and negotiations of individual interests. The different pathways of intergenerational relationships affect cultural transmission in line with the respective culturespecific value orientations and cultural model.

\subsubsection{Lifelong Intergenerational Transmission in Cultural Context}

It is assumed here that the respective cultural models affect individual development and the transmission of values (Chao \& Tseng, 2002; Rothbaum, Weisz, et al., 2000; Stevenson \& Zusho, 2002; Trommsdorff \& Kornadt, 2003). As an example of parent-child relationships in childhood, in the Western context, mothers tend to have their children focus on objects, whereas East Asian mothers prefer close body contact, including co-sleeping; they have their children focus on the relationship, based on empathy, mutual acceptance, relatedness, and assurance. Japanese mothers believe that conformity to social rules cannot be enforced on their children; instead, the children have to mature and believe in those rules and comply with them voluntarily (Lebra, 1994). Here, cultural transmission is based on interdependent parent-child relationships.

Transmission between parents and their adolescent and adult children continues throughout the life span. In East Asian cultures, social obligations toward 
the family and filial piety usually characterize the parent-child relationship over the life span. Asian adolescents and adult children are aware of their parents' sacrifice - especially their mother's. The obligation to reciprocate is based on emotional interdependence and underlies the adult children's motivation to care for adult parents. As part of the Confucian values of seniority and filial piety, the aged parents traditionally receive respect as the "honorable elders" (Palmore \& Maeda, 1985; Wang \& Hsueh, 2000). Furthermore, the shared belief in ancestors and the continuity of the family are part of cultural transmission and continuity in most Asian cultures (Trommsdorff, 2006; in press).

To summarize, cultural transmission occurs during the life span and in cultural context; it is affected by the changing developmental tasks in the parentchild relationship. The process, direction, and outcome of cultural transmission differ depending on the cultural context and the cultural model of independence or interdependence that organizes parent-child relationships over the life span. The study of intergenerational cultural transmission, focusing on the parentchild relationships from a life-span perspective, allows us to address questions of the quality of the parent-child relationship (e.g., with respect to interdependence or independence) and how it affects processes, direction, and outcomes of cultural transmission.

\subsection{EMPIRICAL INVESTIGATION OF INTERGENERATIONAL CULTURAL TRANSMISSION}

\subsection{Research Questions and Methods}

In this section, a currently ongoing cross-cultural study on intergenerational cultural transmission over the life span is briefly summarized. The goals and theoretical assumptions, methods, and selected empirical findings are presented.

Goals and Theoretical Framework of the Study. The general idea underlying this project is the theoretical model on intergenerational cultural transmission (i.e., value of children [ $\mathrm{VOC}]$ and intergenerational relations). The present study attempts to test the theoretical model on the cultural and socioeconomic conditions of cultural transmission, taking into account past and present socialization of parents and children from three biologically related generations, their value orientations, and their relationship quality (Trommsdorff, 200la, 200lb, 2003) (Figure 7.1).

The present study analyzes the different qualitative aspects of parent-child relationships and their function as mediating factors between the culturespecific value orientations (e.g., independence/interdependence, individualism/collectivism, VOC) and the individual investment (e.g., support) in the older or younger generation.

This study starts from an integrated approach (cf. Trommsdorff, 2006, 2007), taking into account ecological and socioeconomic factors, individual value orientations, and the developmental niche as part of the developmental

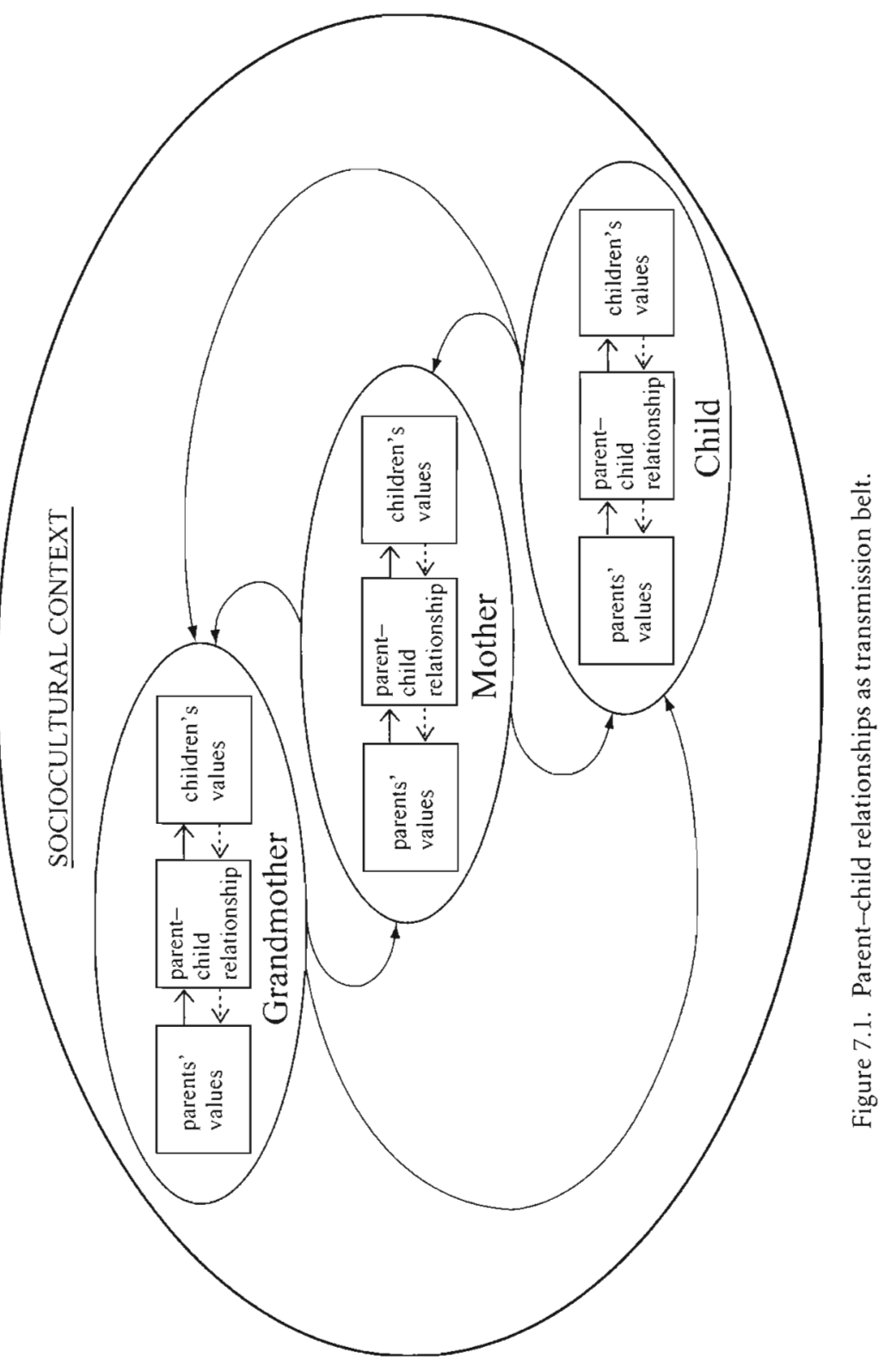


pathway. Beyond the biological connectedness, the shared cultural values concerning childhood, parenthood, and old age are assumed to influence the relationships between parents and their children over the life span and over the generations. The predominant cultural values (e.g., independence or interdependence) affect the pathways for the development of parent-child relationships and the related processes of the cultural transmission.

It is assumed that the parent-child relationship serves as the basis for further interactions, which in turn affect the further development and contribute to the transmission of cultural value orientations and relationship patterns. Furthermore, it is expected that the wider ecological and macro-structure provide both constraints and opportunities for these processes of intergenerational cultural transmission (cf. Nauck, 2001, 2005; Trommsdorff, 2001a, 200lb, 2003, 2006, 2007; Trommsdorff \& Nauck, 2005, 2006).

Thus, the major goal of this project is to study universal and culture-specific relationships among context, value orientations, the quality of parent-child relationships (including the support given and received by parents and children), and their impact on intergenerational (i.e., selective, reciprocal, or unidirectional) transmission over the life course.

Methods. The present study on intergenerational cultural transmission follows a specific design that includes cross-sectional data on three biologically related generations (i.e., grandmothers, mothers, and adolescents) and a control group of young mothers with preschool children and different cultural contexts that represent different value orientations and family systems (i.e., Germany, France, Israel, Palestine, Czech Republic, Turkey, Republic of Korea, People's Republic of China, Indonesia, India, and South Africa). Subgroups in several of these countries (e.g., urban and rural samples) account for intracultural differences. The sample currently consists of more than 10,000 persons.

Procedure. All interviews were undertaken on a face-to-face basis by trained interviewers in each country. The instruments used are questionnaires based on pretests in those countries; they include some established and some newly developed scales to measure the following:

- the quality of the parent-child relationship (e.g., bidirectionality, emotional or instrumental relationship quality)

- value orientations (e.g., independence and interdependence, VOC, value of the family)

- transmission processes (e.g., parenting style)

- transmission outcomes (e.g., similarities, function of transmission for development)

- direction of transmission (e.g., from parents to children, from children to parents) (For a more detailed description, see Schwarz, Chakkarath, Trommsdorff, Schwenk, \& Nauck, 2001; Trommsdorff, 2001a, 200 lb, 2002; Trommsdorff \& Nauck, 2005, 2006.)
First, empirical analyses from this project focused on bidirectional and multidirectional flows of transmission in the cultural context. For persons involved in the transmission process, we focused on grandmothers and mothers, mothers and adolescents, grandmothers, mothers, and adolescents.

\subsection{Preliminary Results on Intergenerational Transmission of Values}

Outcome of Intergenerational Transmission. Similarity of values has often been regarded as indicating the intended "successful" transmission of values from parents to their children due to successful parenting and a positive parentchild relationship (Grusec \& Goodnow, 1994). Cultural values, socioeconomic changes, and developmental tasks may affect the parent-child relationship and moderate the transmission of values between the generations.

In accordance with the model of culture-specific developmental paths (Rothbaum, Pott, et al., 2000), it may be assumed that in countries where values of interdependence are high, similarities in value orientations among the older and younger generations will be stronger than in individualistic societies. Also, fewer similarities among generations and more intragenerational differences (i.e., inconsistencies) are expected in those countries where values of independence are more relevant (and/or where a transition to modernity is taking place). In the latter case, the older generation presumably prefers "modern" values of independence and individualism less than the younger generation, who may prefer both traditional and modern values. Thus, a general preference for individualistic values (and/or a sociocultural change toward modernity) as compared to a general preference for group-oriented (i.e., collectivistic) values on the aggregate level should be related to higher selectivity in the transmission of values, more intergenerational differences, and more intragenerational inconsistencies in value orientations.

(a) In one study, we tested intergenerational differences and similarities with respect to parental goals and values, thus focusing on the parents' intentions for child outcomes. Developmental timetables (i.e., the preferred age levels for the children showing a certain behavioral competence) were used because they indicate cultural values and knowledge about the "ideal" and preferred time of development. We compared mothers and their biological mothers (i.e., grandmothers) with respect to their preferred developmental timetables in German, Korean, and Indonesian samples (i.e., the pilot study) (Schwarz, Trommsdorff, Kim, \& Park, 2006). Whereas differences between the Korean and German mothers and grandmothers occurred, the Indonesian dyads showed no differences. These results demonstrate that disagreements between grandmothers and mothers are less pronounced in a traditional-interdependent culture. In line with this reasoning, we compared developmental goals of German mothers and grandmothers. Here, differences between the two generations occurred in the expected direction: Developmental goals of obedience were more preferred 
and goals of independence were less preferred by grandmothers as compared to mothers (Trommsdorff et al., 2004).

(b) However, because the testing of mean differences in value orientations does not give insight into the meaning of the specific values that are "successfully" transmitted, it is preferable to compare value structures (e.g., by latent class analysis) as a more valid approach to indicate whether and in which way generations differ. This analysis was carried out for a sample of two generations from a country undergoing significant socioeconomic and cultural change: the Czech Republic. Here, grandmothers belonged to a group with high values on all VOC dimensions whereas none of their adult daughters (i.e., mothers of adolescent children) belonged to this group; the adult daughters were represented in a group in which only the emotional VOC was high (Mayer \& Trommsdorff, 2003). However, it must be analyzed in further studies whether those differences indicate effects of value changes or of individual development.

Processes of Intergenerational Transmission. As suggested in our model of intergenerational relations over the life span, the relationship quality between mothers and adolescents should influence the extent of transmission. According to the two-step model (i.e., the accurate perception of a value and its acceptance) by Grusec and Goodnow (1994), it was assumed that intimacy in the relationship and perceived acceptance enhances communication between adolescents and their mothers, thereby increasing the accurate perception and the acceptance of maternal values. In contrast, conflicts between adolescents and their mothers increase the communication about values (cf. Knafo \& Schwartz, 2003 ) but at the same time reduce the accuracy of perception and the acceptance of them.

Cross-cultural studies are needed to study the processes of transmission. This is one goal of our project, "Value of Children and Intergenerational Relations." In a recent study, we investigated how several general and domain-specific value orientations (e.g., individualism/collectivism, family values, and interdependence) are transmitted from one generation to the next (Albert, 2007; Albert \& Trommsdorff, 2003; Albert, Trommsdorff, \& Sabatier, 2005). First, we tested the effects of the parent-child relationship as part of the transmission process for the German and French sample of mothers, grandmothers, and their adolescent children within the framework of the VOC study (Albert, 2007; Albert \& Trommsdorff, 2003). The extent of transmission of values (i.e., general and domain-specific values such as individualism/collectivism, family, and interdependence) and the influence of the parent-child and grandparent-grandchild relationship quality on the extent of transmission of values were tested (i.e., regression analyses). The results showed that all four value orientations of the adolescents were predicted by the value orientations of the mothers. The prediction of individualism, however, was relatively weak in Germany, indicating a rather selective transmission of values. At the same time, mean values of mothers and adolescents on all scales differed in both countries; this indicates a relative as opposed to an absolute transmission. Apart from this, in Germany, intimacy and perceived admiration by parents turned out to be successful transmission belts for values of collectivism and the value of the family but not for individualism and interdependence, thus suggesting the need to refine the model by Grusec and Goodnow (1994) with respect to the contents and meaning of the values. Conflict had no moderating effect on value transmission. In France, any of these aspects of the relationship quality had an effect on transmission. Furthermore, all aspects of the relationship quality had direct effects on the value orientations of the adolescents in both countries. Results on the transmission between grandmothers and their adolescent grandchildren showed an unexpected moderating effect of intimacy on collectivism: The less intimacy was reported, the stronger was the transmission of collectivism in France. Here, a particular function of intergenerational relationships in nonadjacent dyads becomes obvious. Grandmother-grandchild relationships are more hierarchically organized than parent-child relationships, thus affecting the role of intimacy for value transmission. As expected, perceived admiration enhanced the transmission of interdependence from grandmothers to grandchildren, especially in France. These results support the notion that the relationship quality has an important impact on the process of transmission affecting the development of value orientations of adolescents. Furthermore, the results indicate that intergenerational cultural transmission must be studied with respect to the cultural meaning of the values in question and the culture-specific aspects of relationship quality.

In line with the model by Grusec and Goodnow (1994), we also assumed that parenting plays an important role in value transmission (Albert, 2007; Albert, Trommsdorff, \& Sabatier, 2005). To clarify possible culture-specificities in the process of transmission, we tested the role of parenting as a mediator of transmission. The sample consisted of 510 German and French mother-adolescent dyads. The results showed intergenerational transmission of all values in both cultural samples; furthermore, cultural differences in parenting occurred, and parenting had culture-specific effects on the transmission of different values. In Germany, collectivism was transmitted via maternal acceptance and control, and interdependence was transmitted via maternal acceptance. In France, family values were transmitted via maternal control. Thus, culture-specificities in parenting and intergenerational relationships must be considered when explaining processes of transmission.

Furthermore, we studied the role of the cultural context for the transmission of values comparing intergenerational transmission of general and domainspecific values in Germany and Indonesia, two contexts that differ with respect to the developmental path of independence and interdependence (Albert, Trommsdorff, \& Wisnubrata, 2006). Whereas the transmission of individualism was stronger in Indonesian families, the transmission of family values was stronger in German families. Apparently, values that are not shared by the society are rather transmitted within the family, whereas widely shared values are transmitted by various socialization agents, thereby reducing the impact of families on value transmission. 
Beyond the transmission of values, more empirical evidence is needed on the process of transmission of other orientations. For example, attachment - an important personality and relationship variable - has often been assumed to be transmitted from parents to children. However, only scarce empirical evidence is available as far as the processes in the transmission of attachment are concerned. Therefore, as part of the "Value of Children and Intergenerational Relations" study, we compared German and Indian adolescents' and their mothers' attachment and analyzed how far maternal parenting mediates the relationship between mothers' and their adolescent children's attachment (Albert, Trommsdorff, \& Mishra, 2007). The sample consisted of 300 Indian and 310 German mother-adolescent dyads. One major result was that Indian mothers reported using more control than German mothers. Furthermore, control and acceptance as parenting styles were more balanced in the Indian sample as compared to the German sample. In both cultures, attachment of mothers clearly predicted the attachment of adolescent children. However, the relationship between maternal and adolescent attachment was not mediated by parenting. The results are in line with the assumption that cultural pathways of development affect the meaning of parenting and of attachment. However, the specific mediators for the transmission of attachment in the respective cultures still must be clarified. Further studies are needed to identify the influential processes in the transmission of values and other general orientations and to study the moderating effects of culture on those processes.

\subsection{Implications for the Study of Intergenerational Cultural Transmission}

The studies on intergenerational cultural transmission have demonstrated that it is necessary to interpret the "outcomes" of transmission in a theoretical cultureinformed framework and not only focus on single indicators of values and simple comparisons of means between different generations, as in many past studies on transmission. Intergenerational similarities in values measured at a single time-point do not necessarily indicate "successful" cultural transmission, and "unsuccessful" transmission is not necessarily indicated by intergenerational value discrepancies, as can be seen when including intentions of the transmitter and, furthermore, when considering the function of the transmitted orientations in the respective (possibly changing) context. However, other researchers have not made this distinction. Kohn and Schooler (1983) studied value similarities among generations (cohorts) with respect to political orientations, religious beliefs, and lifestyles. They argued that for Western countries, the transmission of values from one generation to the next is very modest and that internalization of values can only seldom be empirically documented. This skeptical summary of intergenerational transmission of values is not confirmed by psychological analyses on intergenerational cultural transmission. The results from our studies show that the implicit assumption that similarity of parents' and children's values indicates "successful" transmission can be wrong due to the more complex problem of selective transmission of values. Comparisons of mean values indicating the degree of "absolute" transmission have to be differentiated from correlations of values between parents and children that indicate "relative" transmission of values (Vermulst, De Brock, \& Van Zutphen, 1991).

From a developmental perspective, intergenerational differences in values can be related to different stages in the individual life cycle and to a different historical impact on socialization. Similarities in values of parents and their children can therefore change in size and pattern during socialization and over the life span, and they can vary in different social groups and according to the respective contents (i.e., subjective meaning) of the values. Therefore, little can be said about "successful" transmission as long as it is unclear what the function of certain values is (e.g., with respect to the person's development). Certain value discrepancies between parents and children may occur for a cer tain period (especially during adolescence and emerging adulthood). The consequence may be more clarity and stability in the resulting later value orientations. Intrapersonal changes of and inconsistencies in values are a normal aspect of development, and discrepancies between values of parents and their children may be due to developmental dynamics, not indicating failure of cultural transmission but rather a certain developmental stage in the internalization of values and in the "successful" cultural transmission. Thus, transmission must be studied from a long-term perspective.

Furthermore, the contents of the values as part of the value system of the family must be considered (Trommsdorff et al., 2004). In a culture where individualistic values prevail, more contradictions, ambiguity, and negotiation of value priorities occur. In this context, different conditions for the transmission of values prevail as compared to traditional cultures, which are characterized by a more homogeneous value system.

To summarize, similarities or differences of single values between parents and their offspring do not tell us much about "successful" transmission. Also, a static perspective assuming direct transmission of values from parents to children and regarding value similarity as an indicator of successful transmission cannot account for the dynamic process of cultural transmission in the cultural context. The pattern and meaning of the values, their behavioral relevance, the quality of the intergenerational relations, and the function of these relationships in the process of transmission in the respective cultural context all have to be assessed in research on intergenerational cultural transmission.

\subsection{OUTLOOK: INTERGENERATIONAL CULTURAL TRANSMISSION AND SOCIOCULTURAL CHANGE}

Intergenerational cultural transmission has been studied in this chapter by considering the quality of the parent-child relationship over the life span in 
different cultural contexts. It has been shown that intergenerational transmission can change over the life span and depends on the development of parent-child relationships; the impact of culture on the transmission of culture through intergenerational relations cannot be ignored.

The transmission of culture may be seen as deriving from the child's internalization of values. However, this does not necessarily imply the child's conformity to parental values. Certain values can be enacted differently and may change their meaning during individual development and social change. Intergenerational transmission of culture can change the relationships between values and behavior and can induce innovations. This assumption takes into account both the active role of the child in the process of transmission and internalization and the heterogeneity of cultures and societies.

Further studies on intergenerational cultural transmission, therefore, should address the questions of how far continuity and stability of culture can be predicted from transmission processes and how far intergenerational relationships and cultural transmission can be seen as a source for innovation and change (Kuczynski \& Navara, 2006; Valsiner, 1988). Therefore, the function of intergenerational relationships for cultural transmission, including selective continuity or drastic change, needs further investigation.

The child's and the parents' activity in the transmission process is influenced by the parent-child relationship and the cultural values. Specific values (e.g., independence) may have different cultural and/or subjective meanings according to the cultural context in which the value is prevalent and the actor's personality (e.g., development, intention, and worldview). A certain behavior may seem to indicate a specific value although it is meant to express a quite different value. Invalid measurement occurs when the cultural and the subjective meaning of the specific observed behavior is not considered. Human behavior may be based on different, even conflicting, motives. For example, compliance may have different meanings: suppressed resistance or fully endorsed internalized acceptance of values. Internalization of certain values can thus give rise to very different forms of behavior. The kind and degree of internalization is more adequately assessed by considering the subjective meaning of only those manifest behaviors that are strongly related to the self-concept. Therefore, the question is raised as to how far deviance from of acceptance of certain cultural values is a part of one's self-construal.

Under certain circumstances - and depending on the cultural context, the developmental age, and the situation - deviance is well accepted and seen as an indicator of successful transmission of values from parents to children. In several cultures (e.g., Japan and China), children are not expected to comply with cultural values and norms in early childhood. Children's noncompliance is regarded as a cultural value of childhood that enhances later successful transmission of values. The modern Japanese Kabuki player is an example of simultaneously cultural compliance and deviance. He should fully comply with traditional cultural norms while on stage; off stage, however, he may engage in "Western"-style modern behavior, thus serving as a model for the continuation and also discontinuation of certain traditional values. Therefore, more has to be known about relationships between the transmission of traditional culture and innovation.

The processes of cultural transmission in times of drastic socioeconomic and cultural change also need to be investigated. Our own studies have shown that ongoing demographic change induces changes in intergenerational relationships and changes in the VOC (from economic to emotional values) (Makoshi \& Trommsdorff, 2002; Nauck, 2000; Trommsdorff \& Nauck, 2006; Trommsdorff, Zengh, \& Tardif, 2002).

Furthermore, the role of the transmission of culture for an individual's development should be clarified. A further task for future research is to study the gene-environment relationships in the process of transmission and its culture specific functions.

\section{REFERENCES}

Ainsworth, M. D. Blehar, M. C., Waters, E., \& Wall, S. (1978). Patterns of attachment: A psychological study of the strange situation. Hillsdale, NJ: Erlbaum.

Albert, I. (2007). Intergenerationale Transmission von Werten in Deutschland und Frankreich. Lengerich, Germany: Pabst Science.

Aibert, I., \& Trommsdorff, G. (2003, August). Intergenerational transmission of family values. Poster presented at the XIth European Conference on Developmental Psychology in Milan, Italy.

Albert, I., Trommsdorff, G., \& Mishra, R. (2007). Parenting and adolescent attachment in India and Germany. In G. Zheng, K. Leung, \& J. G. Adair (Eds.), Perspectives and progress in contemporary cross-cultural psychology. Selected papers from the Seventeenth International Congress of the International Association for Cross-Cultural Psychology (pp. 97-108). Beijing, China: China Light Industry Press.

Albert, I., Trommsdorff, G., \& Sabatier, C. (2005, July). Parenting and intergenerational transmission of values in Germany and France. Paper presented at the 7 th European Regional Congress of the International Association for Cross-Cultural Psychology, San Sebastian, Spain.

Albert, L., Trommsdorff, G., \& Wisnubrata, L. (2006, July). Intergenerationai transmission of values in different cultural contexts: A study in Germany and Indonesia. Paper presented at the 18th International Congress of the IACCP, Spetses, Greece.

Baltes, P. B., \& Baltes, M. M. (1990). Psychological perspectives on successful aging: The model of selective optimization with compensation. In P. B. Baltes \& M. M. Baltes (Eds.), Successful aging: Perspectives from the behavioral sciences (pp. 1-34). Cambridge, UK: Cambridge University Press.

Bandura, A. (1977). Social learning theory. Englewood Cliffs, NJ: Prentice Hall.

Bandura, A. (1986). Social foundations of thought and action: A social cognitive theory. Upper Saddle River, NJ: Prentice-Hall. 
Baumrind, D. (1991). Effective parenting during the early adolescent transition. In P. A. Cowan \& E. M. Hetherington (Eds.), Family transitions: Advances in family research series (pp. 111-163). Hillsdale, NJ: Erlbaum.

Bell, R. Q. (1979). Parent, child, and reciprocal influences. American Psychologist, 34, $821-826$.

Benedict, R. (1934). Patterns of culture. Boston: Houghton Mifflin.

Bengtson, V. L. (2001). Beyond the nuclear family: The increasing importance of multigenerational bonds. Journal of Marriage \& Family, 63, 1-16.

Bengtson, V. L., \& Robertson, J. F. (Eds.). (1985). Grandparenthood. Beverly Hills, CA: Sage Publications.

Berry, J. W. (1967). Independence and conformity in subsistence-level societies. Journal of Personality \& Social Psychology, 7, 415-418.

Berry, J. W., Poortinga, Y. H., Segall, M. H., \& Dasen, P. R. (2002). Cross-cultural psychology: Research and applications (Vol. 2). New York: Cambridge University Press.

Blenkner, M. (1965). Social work and family relationships in later life with some thoughts on filial maturity. In E. Shanas \& G. F. Streib (Eds.), Social structure and the family: Generational relations (pp. 46-59). Englewood Cliffs, NJ: Prentice-Hall.

Bowlby, J. (1969). Attachment and loss: Vol. 1, Attachment. New York: Basic Books.

Bronfenbrenner, U. (1979). The ecology of human development: Experiments by nature and design. Cambridge, MA: Harvard University Press.

Bruner, J. S. (1996). The culture of education. Cambridge, MA: Harvard University Press.

Bugental, D. B., \& Goodnow, J. J. (2000). Socialization processes. In W. Damon \& N. Eisenberg (Eds.), Handbook of child psychology: Vol. 3, Social, emotional, and personality development (5th ed., pp. 389-463). New York: John Wiley \& Sons.

Cavalli-Sforza, L. L., \& Feldman, M. W. (1981). Cultural transmission and evolution: A quantitative approach. Princeton, NJ: Princeton University Press.

Chao, R., \& Tseng, V. (2002). Parenting of Asians. In M. H. Bornstein (Ed.), Handbook of parenting: Vol. 4, Social conditions and applied parenting (2nd ed., pp. 59-93). Mahwah, NJ: Erlbaum.

Cole, M. (1996). Cultural psychology: A once and future discipline. Cambridge, MA: Harvard University Press.

Cole, M., \& Scribner, S. (1974). Culture \& thought: A psychological introduction. New York: Wiley.

Collins, W. A., Maccoby, E. E., Steinberg, L., Hetherington, E. M., \& Bornstein, M. H. (2000). Contemporary research on parenting: The case for nature and nurture. American Psychologist, 55, 218-232.

Cooney, T. M. (1997). Parent-child relations across adulthood. In S. Duck (Ed.), Handbook of personal relationships (2nd ed., pp. 451-468). Chichester, UK: Wiley.

Cooper, C. R., Grotevant, H. D., \& Condon, S.M. (1983). lndividuality and connectedness in the family as a context for adolescent identity formation and role-taking skill. New Directions for Child Development, 22, 43-59.

Corsaro, W. A. (1997). The sociology of childhood. Thousand Oaks, CA: Pine Forge Press. Crocket, L. J., \& Silbereisen, R. K. (Eds.). (2000). Negotiating adolescence in times of social change. Cambridge, UK: Cambridge University Press.

D'Andrade, R. G., \& Strauss, C. (Eds.). (1992). Human motives and cultural models. New York: Cambridge University Press.
Elder, G. H., Jr. (1974). The children of the Great Depression: Social change and life experience. Chicago: University of Chicago Press.

Elder, G. H., Jr. (1998). The life course as developmental theory. Child Development, 69, $1-12$.

Erikson, E. H. (1959). Identity and the life cycle. New York: International University Press.

Fiske, A. P., Kitayama, S., Markus, H. R., \& Nisbett, R. E. (1998). The cultural matrix of social psychology. In D. T. Gilbert, S. T. Fiske, \& G. Lindzey (Eds.), The handbook of social psychology (4th ed., Vol. 2, pp. 915-981). Boston: McGraw-Hill.

Gallese, V. (2003). The roots of empathy: The shared manifold hypothesis and the neural basis of intersubjectivity. Psychopathology, 36, 171-180.

Geertz, C. (1973). The interpretation of cultures: Selected essays. New York: Basic Books.

Goodnow, J. J., \& Collins, W. A. (Eds.). (1990). Development according to parents: The nature, sources, and consequences of parents' ideas. Hillsdale, NJ: Erlbaum.

Greenfield, P. M. (2000). Three approaches to the psychology of culture: Where do they come from? Where can they go? Asian Journal of Social Psychology, 3, 223-240.

Greenfield, P. M., Keller, H., Fuligni, A. J., \& Maynard, A. (2003). Cultural pathways through universal development. Annual Review of Psychology, 54, 461-490.

Grusec, J. E., \& Goodnow, J. J. (1994). Impact of parental discipline methods on the child's internalization of values: A reconceptualization of current points of view. Developmental Psychology, 30, 4-19.

Grusec, J. E., \& Kuczynski, L. (Eds.). (1997). Parenting and the internalization of values: A handbook of contemporary theory. New York: Wiley.

Harkness, S., \& Super, C. M. (2002). Culture and parenting. In M. H. Bornstein (Ed.), Handbook of parenting: Vol. 2, Biology and ecology of parenting (2nd ed., pp. 253-280). Mahwah, NJ: Erlbaum.

Havighurst, R. J. (1972). Developmental tasks and education. New York: MacKay.

Hewlett, B. S., \& Cavalli-Sforza, L. L. (1986). Cultural transmission among Aka pygmies. American Anthropology, 88, 922-934.

Hoffman, J. A. (1984). Psychological separation of late adolescents from their parents. Journal of Counselling Psychology, 31, 170-178.

Holland, D., \& Quinn, N. (Eds.). (1987). Cultural models in language and thought. New York: Cambridge University Press.

Homans, G. C. (1961). Social behavior. New York: Harcourt, Brace \& World.

Kagitcibasi, C. (1996). Family and human development across cultures: A view from the other side. Mahwah, NJ: Erlbaum.

Keller, H. (2002). Development as the interface between biology and culture: A conceptualization of early ontogenetic experiences. In H. Keller, Y. H. Poortinga, \& A. Schölmerich (Eds.), Between culture and biology: Perspectives on ontogenetic development (pp. 215-240). New York: Cambridge University Press.

Kelley, H. H. (1983). Close relationships. New York: Freeman.

Kelley, H. H., \& Thibaut, J. W. (1978). Interpersonal relations: A theory of interdependence. New York: Wiley.

Kim, K. C., Kim, S., \& Hurh, W. M. (1991). Filial piety and intergenerational relationship in Korean immigrant families. International Journal of Aging and Human Development, 33, 233-245. 
King, V., \& Elder, G. H., Jr. (1997). The legacy of grandparenting: Childhood experiences with grandparents and current involvement with grandchildren. Joumal of Marriage
\& Family, 59, 848-859.

Knafo, A., \& Schwartz, S. H. (2003). Parenting and adolescents' accuracy in perceiving parental values. Child Development, 74, 595-611.

Kohli, M., \& Szydlik, M. (Eds.). (2000). Lebenslauf, Alter, Generation: Band 3. Generationen in Familie und Gesellschaft [Life-course, age, generation: Vol. 3. Generation in family and society]. Opladen, Germany: Leske + Budrich.

Kohn, M. L., \& Schooler, C. (1983). Work and personality: An inquiry into the impact of social stratification. Norwood, NJ: Ablex Publishing Corporation.

Kornadt, H.-J., \& Trommsdorff, G. (1984). Erziehungsziele im Kulturvergleich [Childrearing goals in cross-cultural comparison]. In G. Trommsdorff (Ed.), Jahrbuch für Empirische Erziehungswissenschaft 1984: Erziehungsziele (pp. 191-212). Düsseldorf, Germany: Schwann.

Kroeber, A. L., \& Kluckhohn, C. (1952). Culture: A critical review of concepts and definitions. Papers. Peabody Museum of Archaeology \& Ethnology, Harvard University,
$47(1)$.

Kuczynski, L. (2003). Beyond bidirectionality: Bilateral conceptual frameworks for understanding dynamics in parent-child relations. In L. Kuczynski (Ed.), Handbook of dynamics in parent-child relations (pp. 1-24). Thousand Oaks, CA: Sage Publications.

Kuczynski, L., \& Navara, G. (2006). Sources of innovation and change in internalization and socialization. In M. Killen \& J. Smetana (Eds.), Handbook of moral development (pp. 299-327). Mahwah, NJ: Erlbaum.

Lebra, T. S. (1994). Mother and child in Japanese socialization: A Japan-U.S. comparison. In P. M. Greenfield \& R. R. Cocking (Eds.), Cross-cultural roots of minority child development (pp. 259-274). Hillsdale, NJ: Erlbaum.

LeVine, R. A. (1973). Culture, behavior, and personality. Chicago: Aldine.

Maccoby, E. E. (2000). Parenting and its effects on children: On reading and misreading behavior genetics. Annual Review of Psychology, 51, 1-27.

Maccoby, E. E., \& Martin, J. A. (1983). Socialisation in the context of the family: Parentchild interaction. In P. H. Mussen \& E. M. Hetherington (Eds.), Handbook of child psychology: Vol. 4, Socialization, personality and social development (pp. 1-101). New York: Wiley.

Makoshi, N., \& Trommsdorff, G. (2002). Value of children and mother-child relationships in Japan: Comparisons with Germany. In U. Teichler \& G. Trommsdorff (Eds.), Challenges of the 21st century in Japan and Germany (pp. 109-124). Lengerich, Germany: Pabst Science.

Mannheim, K. (1929/1964). Das Problem der Generationen [The problem of the generations]. Köln, Germany: Westdeutscher Verlag.

Markus, H. R., \& Kitayama, S. (1991). Culture and the self: Implications for cognition, emotion, and motivation. Psychological Review, 98, 224-253.

Markus, H. R., \& Kitayama, S. (1994). A collective fear of the collective: Implications for selves and theories of selves. Personality and Social Psychology Bulletin, 20, 568-579.

Matsumoto, D. (1999). Culture and self: An empirical assessment of Markus and Kitayama's theory of independent and interdependent self-construal. Asian Journal of Social Psychology, 2, 289-310.
Mayer, B., \& Trommsdorff, G. (2003, September). Kindbezogene Wertstrukturen bei tschechischen Müttern und Großmüttern /Child-related value structures of Czech mothers and grandmothers]. Poster presented at the 16th Meeting of the Section of Developmental Psychology of the German Psychological Association, Mainz, Germany.

Mead, M. (1935). Sex and temperament in three primitive societies. New York: William Morrow.

Meltzoff, A. N., \& Moore, M. K. (1998). Infant intersubjectivity: Broadening the dialogue to include imitation, identity and intention. In S. Braten (Ed.), Intersubjective communication and emotion in early ontogeny (pp. 47-88). Cambridge, MA: Cambridge University Press.

Nauck, B. (2000). Social capital and intergenerational transmission of cultural capital within a regional context. In J. Bynner \& R. K. Silbereisen (Eds.), Adversity and challenge in life in the new Germany and in England (pp. 212-238). Houndmills, UK: Macmillan.

Nauck, B. (2001). Der Wert von Kindern für ihre Eltern: "Value of children" als spezielle Handlungstheorie des generativen Verhaltens und von Generationenbeziehungen im interkulturellen Vergleich [The value of children for their parents: A special action theory of fertility behavior and intergenerational relationships in cross-cultural comparison]. Kölner Zeitschrift für Soziologie und Sozialpsychologie, 53, 407-435.

Nauck, B. (2005). Changing value of children: An action theory of fertility behavior and intergenerational relationships in cross-cultural comparison. In W. Friedlmeier, P. Chakkarath, \& B. Schwarz (Eds.), Culture and human development: The importance of cross-cultural research in the social sciences (pp. 183-202). Hove, UK: Psychology Press.

Neugarten, B. L. (1968). Middle age and aging: A reader in social psychology. Chicago: University of Chicago Press.

Palmore, E. B., \& Maeda, D. (1985). The honorable elders revisited (Otoshiyori saikô). Durham, NC: Duke University Press.

Plomin, R. (2000). Behavioural genetics in the 21 st century. International Journal of Behavioral Development, 24, 30-34.

Quinn, N., \& Holland, D. (1987). Culture and cognition. In D. Holland \& N. Quinn (Eds.), Cultural models in language and thought (pp. 1-40). New York: Cambridge University Press.

Rogoff, B. (2003). The cultural nature of human development. Oxford, UK: Oxford University Press.

Rohner, R. P., \& Pettengill, S. M. (1985). Perceived parental acceptance-rejection and parental control among Korean adolescents. Child Development, 56, 524-528.

Rothbaum, F., Pott, M., Azuma, H., Miyake, K., \& Weisz, J. (2000). The development of close relationships in Japan and the United States: Paths of symbiotic harmony and generative tension. Child Development, 71, 1121-1142.

Rothbaum, F., \& Trommsdorff, G. (2007). Cultural perspectives on relationships and autonomy-control. In I. E. Grusec \& P. Hastings (Eds.), Handbook of socialization (pp. 461-489). New York: The Guilford Press.

Rothbaum, F., Weisz, I., Pott, M., Miyake, K., \& Morelli, G. (2000). Attachment and culture: Security in the United States and Japan. American Psychologist, 55, 1093-1104.

Rusbult, C. E., \& Van Lange, P. A. M. (2003). Interdependence, interaction and relationships. Annual Review of Psychology, 54, 351-375. 
Schönpflug, U. (2001). Intergenerational transmission of values: The role of transmission belts. Journal of Cross-Cultural Psychology, 32(2), 174-185.

Schwarz, B., Chakkarath, P., Trommsdorff, G., Schwenk, O., \& Nauck, B. (2001). Report on selected instruments of the value of children main study. Unpublished manuscript, University of Konstanz, Konstanz, Germany.

Schwarz, B., Trommsdorff, G., Kim, U., \& Park, Y.-S. (2006). Intergenerational support: Psychological and cultural analyses of Korean and German women. Current Sociology, 54(2), 315-340

Shore, B. (1996). Culture in mind: Cognition, culture, and the problem of meaning. New York: Oxford University Press.

Shweder, R. A. (1991). Thinking through cultures: Expeditions in cultural psychology. Cambridge, MA: Harvard University Press.

Stevenson, H. W., Chen, C., \& Lee, S. (1992). Chinese families. In J. L. Roopnarine \& D. B. Carter (Eds.), Parent-child socialization in diverse cultures (pp. 17-33). Norwood, NJ: Ablex Publishing Corporation.

Stevenson, H. W., \& Zusho, A. (2002). Adolescence in China and Japan: Adapting to a changing environment. In B. B. Brown, R. W. Larson, \& T. S. Saraswathi (Eds.), The world's youth: Adolescence in eight regions of the globe (pp. 141-170). Cambridge, UK: Cambridge University Press.

Super, C. M., \& Harkness, S. (1999). The environment as culture in developmental research. In S. L. Friedman \& T. D. Wachs (Eds.), Measuring environment across the life span: Emerging methods and concepts (pp. 279-323). Washington, DC: American Psychological Association.

Thibaut, J. W., \& Kelley, H. H. (1959). The social psychology of groups. New York: John Wiley and Sons.

Thompson, R. A. (1999). Early attachment and later development. In J. Cassidy \& P. R. Shaver (Eds.), Handbook of attachment: Theory, research, and clinical applications (pp. 265-286). New York: The Guilford Press.

Tomasello, M., Kruger, A. C., \& Ratner, H. H. (1993). Cultural learning. Behavioral and Brain Sciences, 16, 495-552.

Triandis, H. C. (1995). Individualism \& collectivism. Boulder, CO: Westview Press.

Trommsdorff, G. (1985). Some comparative aspects of socialization in Japan and Germany. In I. Reyes Lagunes \& Y. H. Poortinga (Eds.), From a different perspective: Studies of behavior across cultures (pp. 231-240). Amsterdam: Swets \& Zeitlinger.

Trommsdorff, G. (1991). Sympathie und Partnerwahl: Enge Beziehungen aus interkultureller Sicht (Sympathy and partner selection: Close relationships from a crosscultural perspective]. In M. Amelang, H.-J. Ahrens, \& H. W. Bierhoff (Eds.), Partnerwahl und Partnerschaft: Formen und Grundlagen partnerschaftlicher Beziehungen (pp. 185-219). Göttingen, Germany: Hogrefe.

Trommsdorff, G. (1995a). Parent-adolescent relations in changing societies: A crosscultural study. In P. Noack, M. Hofer, \& J. Youniss (Eds.), Psychological responses to social change: Human development in changing environments (pp. 189-218). Berlin, Germany: De Gruyter.

Trommsdorff, G. (1995b). Person-context relations as developmental conditions for empathy and prosocial action: A cross-cultural analysis. In T. A. Kindermann \& J. Valsiner (Eds.), Development of person-context relations (pp. 113-146). Hillsdale, NJ: Erlbaum.
Trommsdorff, G. (2000). Subjective experience of social change in individual development. In J. Bynner \& R. K. Silbereisen (Eds.), Adversity and challenge in life in the new Germany and in England (pp. 87-122). Basingstoke, UK: Macmillan Press.

Trommsdorff, G. (2001a). Eltern-Kind-Beziehungen im interkulturellen Vergleich [Parent-child relations in cross-cultural comparison]. In S. Walper \& R. Pekrun (Eds.) Familie und Entwicklung: Perspektiven der Familienpsychologie (pp. 36-62). Göttingen, Germany: Hogrefe.

Trommsdorff, G. (2001b). Value of children and intergenerational relations: A cross-cultural psychological study. Retrieved May 21, 2008, from http://www.unikonstanz.de/FuF/SozWiss/fg-psy/ag-entw/.

Trommsdorff, G. (2002). An eco-cultural and interpersonal relations approach to development over the life span. In W. J. Lonner, D. L. Dinnel, S. A. Hayes, \& D. N. Sattler (Eds.), Online Readings in Psychology and Culture (Unit 12, Chapter 1) (http://www. wwu.edu/ culture), Center for Cross-Cultural Research, Western Washington University, Bellingham, WA.

Trommsdorff, G. (2003). Parent-child relations in the life span: A cross-cultural perspective. In Korean Association of Child Studies (Ed.), Parental beliefs, parenting, and child development from developmental perspectives (pp. 9-66). Seoul, Republic of Korea: Korean Association of Child Studies.

Trommsdorff, G. (2006). Parent-child relations over the life span. A cross-cultural perspective. In K. H. Rubin \& O. B. Chung (Eds.), Parenting beliefs, behaviors, and parentchild relations. A cross-cultural perspective (pp. 143-183). New York: Psychology Press.

Trommsdorff, G. (2007). Entwicklung im kulturellen Kontext [Development in cultural context]. In G. Trommsdorff \& H.-J. Kornadt (Eds.), Enzyklopädie der Psychologie: Themenbereich C Theorie und Forschung, Serie VII Kulturvergleichende Psychologie. Band 2: Erleben und Handeln im kulturellen Kontext (pp. 435-519). Göttingen, Germany: Hogrefe.

Trommsdorff, G. (in press). Socialization of self-regulation for achievement in cultural context: A developmental-psychological perspective on the Asian miracle. In U. Kim \& Y.-S. Park (Eds.), Asia's educational miracle: Psychological, social, and cultural perspectives. New York: Springer Press.

Trommsdorff, G., \& Dasen, P. R. (2001). Cross-cultural study of education. In N. J. Smelser \& P. B. Baltes (Eds.), International encyclopedia of the social and behavioral sciences (pp. 3003-3007). Oxford, UK: Elsevier.

Trommsdorff, G., \& Friedlmeier, W. (2004). Zum Verhältnis zwischen Kultur und Individuum aus der Perspektive der kulturvergleichenden Psychologie [The relation between culture and the individual in cross-cultural perspective]. In A. Assmann, U. Gaier, \& G. Trommsdorff (Eds.), Positionen der Kulturanthropologie (pp. 358-386). Frankfurt am Main, Germany: Suhrkamp.

Trommsdorff, G., \& Kornadt, H.-J. (2003). Parent-child relations in cross-cultural perspective. In L. Kuczynski (Ed.), Handbook of dynamics in parent-child relations (pp. 271-306). London: Sage Publications.

Trommsdorff, G., \& Mayer, B. (2005). Kulturvergleichende Ansätze [Cross-cultural approaches]. In H. Weber \& T. Rammsayer (Eds.), Handbuch der Persönlichkeitspsychologie und Differentiellen Psychologie. Handbuch der Psychologie [Handbook of Personality Psychology and Psychology of Individual Differences, Handbook of Psychology] (pp. 220-228). Göttingen, Germany: Hogrefe. 
Trommsdorff, G., Mayer, B., \& Albert, I. (2004). Dimensions of culture in intra-cultural comparisons: Individualism/collectivism and family-related values in three generations. In H. Vinken, J. Soeters, \& P. Ester (Eds.), Comparing cultures: Dimensions of culture in a comparative perspective (pp. 157-184). Leiden, the Netherlands: Brill Academic Publishers.

Trommsdorff, G., \& Nauck, B. (Eds.). (2005). The value of children in cross-cultural perspective: Case studies from eight societies. Lengerich, Germany: Pabst Science.

Trommsdorff, G., \& Nauck, B. (2006). Demographic changes and parent-child relationships. Parenting: Science and Practice, 6(4), 343-360.

Trommsdorff, G., \& Rothbaum, F. (2008). Development of emotion regulation in cultural context. In S. Ismer, S. Jung, S. Kronast, C. v. Scheve, \& M. Vandekerckhove (Eds.), Regulating emotions: Social necessity and biological inheritance (pp. 85-120). London/New York: Blackwell.

Trommsdorff, G., Zheng, G., \& Tardif, T. (2002). Value of children and intergenerational relations in cultural context. In P. Boski, F. J. R. van de Vijver, \& A. M. Chodynicka (Eds.), New directions in cross-cultural psychology. Selected papers from the 15 th International Conference of the International Association for Cross-Cultural Psychology (pp. 581-601). Warszawa, Poland: Polish Psychological Association.

Valsiner, J. (1988). Epilogue: Ontogeny of co-construction of culture within socially organized environmental settings. In J. Valsiner (Ed.), Social co-construction and environmental guidance in development (pp. 283-297). Westport, CT: Ablex Publishing.

Vermulst, A. A., De Brock, A. J. L. L., \& Van Zutphen, R. A. H. (1991). Transmission of parenting across generations. In P. K. Smith (Ed.), The psychology of grandparenthood (pp. 100-122). London: Routledge.

Vygotsky, L. S. (1962). Thought and language (E. Hanfmann \& G. Vakar, Trans.). Cambridge, MA: The MIT Press.

Wang, Q., \& Hsueh, Y. (2000). Parent-child interdependence in Chinese families: Change and continuity. In C. Violato, E. Oddone-Paolucci, \& M. Genuis (Eds.), The changing family and child development (pp. 60-69). Aldershot, UK: Ashgate.

Worthman, C. M. (1999). Epidemiology of human development. In C. Panter-Brick \& C. M. Worthman (Eds.), Hormones, health, and behavior: A socio-ecological and life span perspective (pp. 47-104). New York: Cambridge University Press.

Wundt, W. (1900-1920). Völkerpsychologie: Eine Untersuchung der Entwicklungsgesetze von Sprache, Mythus und Sitte [Völkerpsychologie: An analysis on the developmental laws of language, myths, and customs] (10 Vols.). Leipzig, Germany: Engelmann \& Kröner.

Yamagishi, T., Cook, K. S., \& Watabe, M. (1998). Uncertainty, trust, and commitment formation in the United States and Japan. American Journal of Sociology, 104, 165-194.

Zarit, S. H., \& Eggebeen, D. J. (2002). Parent-child relationships in adulthood and later years. In M. H. Bornstein (Ed.), Handbook of parenting: Vol. 5, Practical issues in parenting (2nd ed., pp. 135-161). Mahwah, NJ: Erlbaum. 


\section{Cultural Transmission}

PSYCHOLOGICAL, DEVELOPMENTAL, SOCIAL, AND METHODOLOGICAL ASPECTS

Edited by

Ute Schönpflug

Free University of Berlin

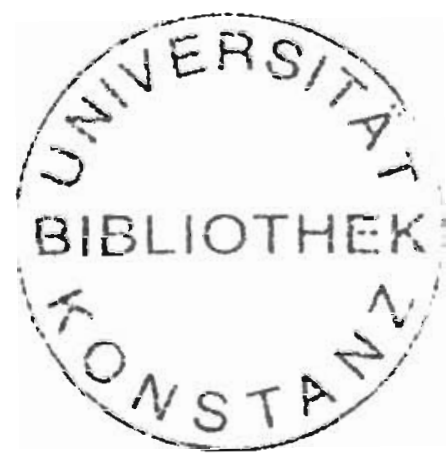

闇 CAMBRIDGE

4. UNIVERSITY PRESS 


\section{ONTENTS}

Cambridge University Press

32 Avenue of the Americas, New York, NY 10013-2473, USA

www.cambridge.org

Information on this title: www.cambridge.org/9780521706575

(c) Cambridge University Press 2009

This publication is in copyright. Subject to statutory exception and to the provisions of relevant collective licensing agreements, no reproduction of any part may take place without the written

permission of Cambridge University Press.

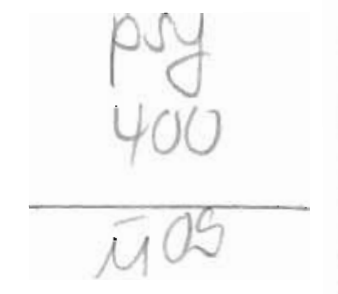

Foreword

David Matsumoto

First published 2009

Printed in the United States of America

Contributors

1. Introduction to Cultural Transmission: Psychological, Developmental, Social, and Methodological Aspects

A catalog record for this publication is available from the British Library.

2. Theory and Research in Cultural Transmission: A Short History

Ute Schönpflug

Cultural transmission : psychological, developmental, social, and methodological aspects / edited by Ute Schönpflug.

$$
\text { p. cm. - (Culture and psychology) }
$$

Includes index.

ISBN 978-0-521-88043-5 (hardback) - ISBN 978-0-521-70657-5 (pbk.) 1. Socialization.

2. Ethnopsychology. 3. Cognition and culture. 4. Learning-Social aspects. 5. Learning Psychology of. I. Schönpflug, Ute, 1940- II. Title. III. Series.

GN510.C83 2008

$303.3^{\prime} 2-d c 22$

2008029336

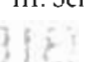

ISBN $\quad 978-0-52 \mathrm{l}-88043-5 \mathrm{hardback}$

ISBN 978-0-521-70657-5 paperback

Cambridge University Press has no responsibility for the persistence or accuracy of URLs for external or third-party Internet Web sites referred to in this publication and does not guarantee that any content on such Web sites is, or will remain, accurate or appropriate. Information regarding prices, travel timetables, and other factual information given in this work are correct at the time of first printing, but Cambridge University Press does not guarantee the accuracy of such information thereafter.

\section{PART ONE: EVOLUTIONARY PERSPECTIVE}

3. Cultural Transmission: A View from Chimpanzees and Human Infants Michael Tomasello

4. Transmission, Self-Organization, and the Emergence of Language: A Dynamic Systems Point of View Paul van Geert

5. Relationship-Specific Intergenerational Family Ties: An Evolutionary Approach to the Structure of Cultural Transmission

Harald A. Euler, Sabine Hoier, and Percy A. Rohde

PART TWO: CROSS-CULTURAL PERSPECTIVE

6. An Ecocultural Perspective on Cultural Transmission: The Family across Cultures

John W. Berry and James Georgas 
7. Intergenerational Relations and Cultural Transmission Gisela Trommsdorff

19. Value Transmission and Zeitgeist Revisited Klaus Boehnke, Andreas Hadjar, and Dirk Baier

8. Intergenerational Transmission, Social Capital, and Interethnic Contact in Immigrant Families

20. Epilogue: Toward a Model of Cultural Transmission Ute Schönpflug Bernhard Nauck

9. Developmental Processes Related to Intergenerational Transmission of Culture: Growing Up with Two Cultures

10. The Transmission Process: Mechanisms and Contexts Ute Schönflug and Ludwig Bilz

11. Accounting for Parent-Child Value Congruence: Theoretical Considerations and Empirical Evidence Ariel Knafo and Shalom H. Schwartz

12. Culture, Migration, and Family-Value Socialization: A Theoretical Model and Empirical Investigation with Russian-Immigrant Youth in Israel Ariel Knafo, Avi Assor, Shalom H. Schwartz, and Limor David

13. Immigrant Parents' Age Expectations for the Development of Their Adolescent Offspring: Transmission Effects and Changes after Immigration Eva Schmitt-Rodermund and Rainer K. Silbereisen

PART THREE: INTRACULTURAL VARIATIONS

14. Intergenerational Transmission of Moral Capital across the Family Life Course Merril Silverstein and Stephen J. Conroy

15. Similarity of Life Goals in the Family: A Three-Generation Study Alexander Grob, Wibke Weisheit, and Veronica Gomez

16. The Intergenerational Transmission of Xenophobia and Rightism in East Germany Bernd Six, Kristina Geppert, and Ute Schönpflug

17. Intergenerational Transmission of Violence Haci-Halil Uslucan and Urs Fuhrer

18. "Don't Trust Anyone over 25": Youth Centrism, Intergenerational Transmission of Political Orientations, and Cultural Change

Tom F. M. ter Bogt, Wim M. J. Meeus, Quinten A. W. Raaijmakers, Frits van Wel, and Wilma A. M. Vollebergh 